\title{
Terapias alternativas precisam de uma ciência alternativa
}

David Marçal*

A história do século XX atesta o sucesso da ciência, não só na medicina como em muitas outras áreas. Mas, e apesar da democratização dos níveis cada vez mais elevados de educação em muitos países, não assistimos a uma equivalente afirmação da cultura científica. Segundo o astrónomo e divulgador científico Carl Sagan, "nós vivemos numa sociedade extraordinariamente dependente da ciência e da tecnologia, em que quase ninguém sabe alguma coisa sobre ciência e tecnologia". Este paradoxo é um terreno fértil para propagar ideias falsamente científicas.

As terapias alternativas socorrem-se de um vasto leque de argumentos para se validarem, como a sua antiguidade, tradição ou ligação à natureza. Mas também alegam terem um fundamento científico. Como se a ciência moderna tivesse confirmado o que era sabido há muito. E não é de todo improvável. Veja-se o caso do extrato de salgueiro, usado tradicionalmente como analgésico e que contém ácido salicílico, que num único passo sintético pode ser convertido em ácido acetilsalicílico, comercializado pela Bayer sob a designação de aspirina. Sendo possível, a questão é se é efetivamente o caso da generalidade dos tratamentos oferecidos pelas terapias alternativas.

\section{QUE PROVAS TÊM AS TERAPIAS ALTERNATIVAS?}

Centro-me em dois exemplos, pela sua enorme popularidade: homeopatia e acupuntura.

A homeopatia, uma prática inventada há cerca de 230 anos, baseia-se (entre outras ideias) no princípio das diluições infinitesimais. Uma coisa qualquer (desde abelhas esmagadas a cicuta) é sujeita a um grande número de diluições seguidas. O remédio homeopático mais popular para a gripe é preparado através de 200 diluições centésimais sucessivas. Como não se pode

*Bioquímico e divulgador de ciência. Ciência Viva - Agência Nacional Para a Cultura Científica e Tecnológica. dividir indefinidamente uma certa quantidade de matéria, porque a partir de certa altura ficamos com menos do que um átomo ou uma molécula, nada resta nos remédios homeopáticos, a não ser água e açúcar. São placebos. Sem surpresa é isso que mostram os ensaios clínicos. Revisão atrás de revisão, feita de modo sério, chega a esta conclusão. Como exemplo posso referir um estudo australiano, ${ }^{1}$ conduzido pelo National Health and Medical Research Council. Considerados 176 ensaios clínicos e 57 revisões sistemáticas, que incidiam sobre 68 condições clínicas, a homeopatia provou ser eficaz no tratamento de nenhuma. É claro que é sempre possível escolher a dedo um ensaio clínico ou outro com graves falhas metodológicas, em que a homeopatia parece funcionar. É isso que fazem os seus apologistas mais sofisticados.

No caso da acupuntura, há que reconhecer a dificuldade na realização de ensaios clínicos. É difícil ter um grupo um controlo, porque não se pode comparar uma intervenção dramática com o efeito de um comprimido de açúcar. A melhor abordagem será usar agulhas retrateis, ${ }^{2}$ que simulam a inserção. No entanto, o acupuntor sabe se está a fazer acupuntura simulada ou não. O melhor que se pode fazer neste caso é que a avaliação da condição clínica seja feita por outra pessoa, que não saiba a que tipo de acupuntura o doente foi sujeito. Claro que nem todos os ensaios clínicos são realizados dessa forma. Muitos ensaios favoráveis à acupuntura comparam o tratamento com a ausência de tratamento e estão na realidade a avaliar o efeito placebo da acupuntura. Boa parte do debate centra-se nesta argumentação metodológica, com os defensores da acupuntura a procurarem impôr ensaios clínicos metodologicamente defeituosos. Uma revisão ${ }^{3}$ de 35 revisões sistemáticas para qualquer condição clínica, publicada em 2006, concluiu que as revisões sistemáticas que apoiam o uso da acupuntura tendem a usar ensaios com problemas conhecidos de enviesamento de resultados. 


\section{LEGISLAÇÃO EM VEZ DE PROVAS}

O panorama geral para os tratamentos alternativos é a falta de provas convincentes da sua eficácia e segurança, como atestam as revisões sistemáticas da Cochrane Collaboration. Não obstante, as terapias alternativas gozam de um grande estatuto e respeitabilidade. No nosso país assistimos a uma notável avalanche legislativa a partir de 2013. Nesse ano foi publicada a Lei n. ${ }^{\circ} 71 / 2013$, que regulamenta o exercício das terapeuticas nao convencionais. Prevê a emissão de cédulas profissionais pela Administração Central do Sistema de Saúde, que passam a determinar o uso dos títulos respetivos (homeopata, acupuntor, etc.). Para as obter é necessária uma licenciatura numa das terapias (quem à data da publicação da lei já exerça, pode dispensar a licenciatura mediante uma análise curricular). Em outubro de 2014 foram publicadas sete portarias (207-A/2014 a 207-G/2014) que fixam “a caracterização e o conteúdo funcional" das profissões de naturopata, osteopata, homeopata, quiroprático, fitoterapeuta, acupuntor e especialista de medicina tradicional chinesa. O conteúdo destas portarias é constrangedor. Quase todas são definidas como "uma abordagem holística, energética e natural do ser humano”, o que não significa absolutamente nada. Em junho de 2015 foram publicadas mais cinco (172-B/2015 a 172-F/2015) que definem os requisitos das licenciaturas em fitoterapia, acupuntura, quiropráxia, osteopatia e naturopatia. No caso da naturopatia, a formação contempla a auricoloterapia, que se baseia na ideia de que a orelha é uma espécie de boneca vodu que representa o corpo todo e que, a cada ponto do pavilhão auricular, corresponde um órgão ou uma parte do corpo. Ou seja, o poder político impôs conteúdos programáticos para um conjunto de licenciaturas, de modo a que estas consubstanciem uma profissão reconhecida por lei, com a concomitante atribuição de cédulas profissionais emitidas pelas autoridades de saúde. Parece-me difícil negar que toda esta embalagem legislativa não tenha o efeito de conferir uma aura de validade científica às terapias alternativas. Por via legislativa procura-se impor uma validação que estas não obtêm através da ciência. Paradoxalmente, se as terapias alternativas conseguissem de facto apresentar provas da sua eficácia e segurança não necessitariam de legislação especial. Fariam aprovar os tratamentos como quaisquer outros e a academia incluiria com naturalidade os seus conteúdos nas formações que oferece. Afinal, falta de procura estes temas não têm.

\section{PORQUE É QUE PESSOAS INTELIGENTES RECORREM ÀS TERAPIAS ALTERNATIVAS?}

$O$ arsenal de argumentos é impressionante. A falta de cultura científica será talvez parte da explicação, mas não será só isso. Socorro-me de uma história pessoal. Quando preparava uma crónica para a revista Notícias Magazine 4 acerca de "Tretas para deixar de fumar" telefonei para uma clínica que dá uns choques nas orelhas com essa finalidade. $\mathrm{O}$ atendimento foi extraordinário. Eu, que nunca fumei, senti que aquela pessoa estava preocupada comigo e me queria ajudar. Talvez seja isso que as pessoas procuram nas terapias alternativas. Uma sensação de acolhimento, que sintam que talvez se tenha perdido nalguns contextos de medicina convencional. Como paciente posso testemunhar que essa convicção é muitas vezes injustificada. Mas penso que ela é explorada pelos partidários das terapias alternativas. Talvez faça sentido refletir sobre formas de a esvaziar.

\section{REFERÊNCIAS BIBLIOGRÁFICAS}

1. National Health and Medical Research Council. NHMRC statement on homeopathy and NHMRC information paper: evidence on the effectiveness of homeopathy for treating health conditions [homepage]. Sidney: NHMRC, Australian Government; 2015 [updated 2015 Jun 25]. Available from: http://www.nhmrc.gov.au/guidelines-publications/ cam02

2. Park J, White A, Stevinson C, Ernst E, James M. Validating a new nonpenetrating sham acupuncture device: two randomised controlled trials. Acupunct Med. 2002;20(4):168-74.

3. Derry CJ, Derry S, McQuay HJ, Moore RA. Systematic review of systematic reviews of acupuncture published 1996-2005. Clin Med (Lond). 2006;6(4):381-6.

4. Marçal D. As tretas para deixar de fumar. Notícias Magazine [Internet]. 2016 Feb 21. Available from: http://www.noticiasmagazine.pt/2016/ as-tretas-para-deixar-de-fumar/

\section{CONFLITOS DE INTERESSE}

O autor declara não ter qualquer conflito de interesses.

\section{ENDEREÇO PARA CORRESPONDÊNCIA}

david.marcal@gmail.com 